\title{
Active management of third stage of labour with low doses of oral misoprostol and oxytocin on low: risk parturient in a Sub-Saharan hospital, Dakar, Sénégal
}

\section{Moussa Diallo*, Toura Sylla, Abdoul Aziz Diouf, Phillipe Marc Moreira, Omar Gassama, Mame Diarra Ndiaye Gueye, Marie Edouard Faye Dieme, Mouhamadou Mansour Niang, Jean Charles Moreau, Alassane Diouf}

Department of Obstetrics and Gynecology, University Cheikh Anta Diop de Dakar, Senegal

Received: 27 October 2016

Accepted: 28 November 2016

\section{*Correspondence:}

Dr. Moussa Diallo,

E-mail: moussadiallo25@hotmail.com

Copyright: () the author(s), publisher and licensee Medip Academy. This is an open-access article distributed under the terms of the Creative Commons Attribution Non-Commercial License, which permits unrestricted non-commercial use, distribution, and reproduction in any medium, provided the original work is properly cited.

\section{ABSTRACT}

Background: Assess the effectiveness of oral misoprostol as an alternative to oxytocin in the active management of the third stage of labour in Dakar/Senegal.

Methods: Randomized controlled clinical trial conducted in the maternity ward of a university hospital on 304 women who had vaginal delivery. These women were randomly assigned into 2 groups based on active delivery conditions: the first group received an oral administration of misoprostol $(400 \mathrm{mcg})$ and the second group 5 IU oxytocin through intravenous route.

Results: The average volume of blood loss was $196.55 \mathrm{ml}$ in the misoprostol group and $208.39 \mathrm{ml}$ in the oxytocin group $(\mathrm{p}=0.63)$. The incidence of postpartum haemorrhage $(>500 \mathrm{cc})$ was $6.49 \%$ in the misoprostol group and $9.33 \%$ in the oxytocin group $(\mathrm{p}=0.358)$. The average rate of haemo globin decline was $0.38 \mathrm{~g} / \mathrm{dl}$ in the misoprostol group and $0.29 \mathrm{~g} / \mathrm{dl}$ in the oxytocin group $(\mathrm{p}=0.99)$. The proportion of hyperthermia, shivering, and nausea in the misoprostol and oxytocin groups were respectively: $2.59 \%$ against $0.6 \%(\mathrm{p}=0.123), 7.14 \%$ against $2 \%(\mathrm{p}=0.001)$ and $2.59 \%$ against $0.6 \%(\mathrm{p}=0.498)$.

Conclusions: In Senegal, Misoprostol despite its side effects, is an effective alternative to oxytocin in the active management of the third stage of labour for low-risk parturient women to reduce the risk of maternal deaths due to post-partum hemorrhage.

Keywords: Active management of the third stage of labour, Delivery, Misoprostol, Post-partum hemorrhage

\section{INTRODUCTION}

Maternal mortality is a global public health concern accounting for nearly 600.000 deaths a year worldwide with $99 \%$ of these deaths occurring in developing countries. At least a quarter of these deaths is due to postpartum haemorrhage (PPH). mostly as a result of uterine atony $(70$ to $80 \%) .{ }^{1}$ In Senegal. maternal mortality was estimated at 401 for 100.000 live births. and PPH accounts for $25 \%$ of maternal deaths. ${ }^{2}$ Yet these deaths due to uterine atony can be avoided in most cases. especially when preventive measures are taken. such as the active management of the third stage of labour (AMTSL) in particular. The latter has proven to be more effective than physiological/expectant management with regard to the duration of labour the frequency of PPH and of post-partum anemia as well as blood transfusion needs. ${ }^{3-6}$ Though oxytocin may be the "gold standard" for AMTSL drawbacks relating to its lack of thermal stability and its administration through parenteral route make misoprostol recognized for its strong uterotonic properties low-cost thermal and light stability over 
several years as well as its multiple and simple routes of administration and despite its side effects an interesting alternative in tropical and low-income countries such as Senegal.

Several studies assessing the benefits of misoprostol in AMTSL for the prevention of PPH in comparison to oxytocin and/or syntometrine seem to unanimously agree on the higher incidence of side effects with misoprostol. But lead to differing and sometimes contradictory results regarding its effectiveness. ${ }^{7-12}$ Indeed misoprostol or oxytocin doses and routes of administration were wideranging in these studies; moreover active delivery techniques were not always clearly stated or differed from one study to the other.

A large-scale multicentre study conducted by WHO reported that oral misoprostol $(600 \mathrm{mcg})$ administered for use with AMTSL was not as effective as oxytocin (10 IU IM) to reduce severe PPH (over $1.000 \mathrm{cc}$ ) in a hospital setting (4 versus $3 \%$ ). ${ }^{13.14}$ The study concluded that there was insufficient evidence to recommend the use of misoprostol for the prevention of PPH when oxytocin was available. and that misoprostol despite its lesser efficacy should still be considered a useful alternative in countries where uterotonics are not generally administered to women.

The purpose of this trial was to assess within our work environment in Senegal the effectiveness of a minimal dose of misoprostol administered via a simple route comparing it to the minimal effective dose of oxytocin generally administered in our services for use with AMTSL to prevent PPH.

\section{METHODS}

The objectives of this randomized clinical trial were to compare the effectiveness of $400 \mathrm{mcg}$ of oral misoprostol to a 5 IU intravenous dose of oxytocin for use in AMTSL based on clinical parameters (blood loss. systolic and diastolic blood pressure) biological parameters (haemoglobin rate. haematocrit value) and supplementary treatments (administration of oxytocics. artificial delivery and/or examination of the uterus. blood transfusion) and to assess tolerance to this oral dose of misoprostol by observing the frequency of adverse effects.

The study was conducted from 1 March to 31 December 2014. i.e. over a period of 10 months at the Gynaecology and Obstetrical Unit of the Centre Hospitalier National de Pikine (Dakar. Senegal) which registers 2.500 births per year on average.

The sample size was calculated taking into account a PPH frequency rate of $5 \%$ a confidence level of 1.96 a power of $80 \%$ and a $5 \%$ margin of error.

Eligible patients were those that gave their consent were at least 36 weeks pregnant and had vaginal delivery at our
Unit. We did not include: unconscious patients (coma. eclampsia. etc.) who could not give their consent. those for whom a cesarean delivery was planned or decided during labour and those with asthma allergy to misoprostol a pregnancy of less than 36 weeks temperature above $38^{\circ} \mathrm{C}$. amniotic infection a multiple pregnancy severe cardiopathy severe anemia coagulopathy or a total or complicated perineal tear. Eligible patients signed a consentment form upon admission in the delivery room.

Eligible patients were included at the end of the second stage of labour when vaginal delivery was decided as the mode of delivery either in the misoprostol or the oxytocin group. The latter being considered as the control group. A computer-generated randomized sequence was conducted earlier. Cards assigning patients into groups were placed in envelopes which were then sealed and numbered as and when patients were included. Misoprostol was available in $200 \mathrm{mcg}$ tablets and oxytocin in $5 \mathrm{IU}$ injectable vials. As soon as the women delivered they were either orally administered $400 \mathrm{mcg}$ of misoprostol (2 tablets) or 5 IU of oxytocin through intravenous route by the resident on duty. If an oxytocin drip was used during labour. it was continued for patients in the "oxytocin" group and replaced by a bottle of $5 \%$ glucose solution in the "misoprostol" group. The patient was then attended by the midwife who was not informed of the type of uterotonic administered. In both groups the umbilical cord was clamped and cut at birth and other AMTSL procedures observed: controlled cord traction. Examination of the placenta and uterine massage for 15 minutes. Patients were monitored in the delivery room for at least 2 hours. The blood lost was collected in a basin placed after the clamping of the umbilical cord and the removal of the amniotic fluid. Episiotomies were repaired immediately after delivery. Blood loss was collected for up to 2 hours after delivery. This blood was transferred into a graduated jar to measure its exact volume. Blood pressure and blood counts were monitored both during labour and two hours after delivery. Side effects usually associated with misoprostol were routinely sought during the early postpartum period for 12 hours. Shivering was directly observed or the patient simply questionned. Axillary temperature was taken using a mercury thermometer. The child was put to the breast within this period. In the event of postpartum haemorrhage support was provided without delay in conformity with our protocol. Methylergometrine was orally administered to all patients as soon as they left the delivery room (1 tablet 2 times a day).

Information on each patient was recorded on a data sheet. These included socio-demographic data (age. pregnancy order and parity) clinical data (blood pressure before and 2 hours after delivery. body mass index (BMI). haemorrhagic shock after delivery. gestational age. volume of blood loss. weight of newborn). paraclinical data (haemoglobin and haematocrit values before and 2 hours after delivery) and therapeutical data 
(administration of supplementary oxytocics. blood transfusions and performance of artificial delivery and/or uterine examination).

Data was entered and analyzed using the software SPSS 11.0. 13.0 And Epi Info 6.04d Fr. To determine the effects of misoprostol in preventing haemorrhage during delivery. We performed a comparative analysis of results obtained in the misoprostol group to those of the control group (oxytocin). The Student " $\mathrm{t}$ " test was used to compare averages and percentages the $\chi 2$ or Fischer test to compare categorical variables whereas Fisher's exact test was used where the number in some groups was less than 5. The significance level of the $\mathrm{p}$ value was 0.05 . The study protocol received ethical endorsement from the hospital's medical committee. The figure1 resume the study subject flow.

The general characteristics of patients in both misoprostol and oxytocin groups were comparable (Table 1): mean age. mean parity. mean body mass index. mean gestational age. mean weight of newborns. and number of episiotomies.

Table 1: General characteristics of the groups.

\begin{tabular}{|c|c|c|c|}
\hline & Misoprostol & Oxytocin & \\
\hline & $\mathbf{N}=154$ & $N=150$ & $\mathbf{P}$ \\
\hline & Average & Average & \\
\hline Age (years) * & 27 & 27 & 0.55 \\
\hline Parity * & 2.49 & 2.51 & 0.99 \\
\hline BMI $\left(\mathrm{Kg} / \mathrm{m}^{2}\right) *$ & 25.71 & 25.79 & 0.82 \\
\hline $\begin{array}{l}\text { Gest Term (WA) } \\
*\end{array}$ & 39.6 & 39.5 & 0.16 \\
\hline $\begin{array}{l}\text { NBorn weight } \\
(\mathrm{g}) *\end{array}$ & 2969 & 3027 & 0.03 \\
\hline $\begin{array}{l}\text { Episiotomy } \\
\text { (number)* }\end{array}$ & 47 & 40 & 0.45 \\
\hline
\end{tabular}

BMI = Body Mass Index (Kg/mètre 2); WA = weeks of amenorrhea; $\mathrm{N}$ Born $=$ newborn; $\mathrm{g}=$ gramme* Student test $\mathrm{t}$; ** Khi 2 test.

\section{RESULTS}

The 2 groups were comparable in terms of changes in systolic and diastolic blood pressures before and after delivery (Table 2). An average reduction of systolic blood pressure by $0.7 \mathrm{~mm} \mathrm{Hg}$ was observed in the misoprostol group against $0.89 \mathrm{~cm} \mathrm{Hg}$ in the oxytocin group $(\mathrm{p}=0.189)$. There was no significant difference in the average reduction of diastolic blood pressure for both groups: $0.54 \mathrm{~cm} \mathrm{Hg}$ in the misoprostol group against 0.5 $\mathrm{cm} \mathrm{Hg}$ in the control group ( $\mathrm{p}=0.458)$.

In terms of blood loss there was no statistically significant difference between the groups (Table 3). The average volume of blood loss was $196.55 \mathrm{ml}$ in the misoprostol group and $208.39 \mathrm{ml}$ in the oxytocin group (p $=0.63)$. Proportions of postpartum haemorrhage $(>500$ $\mathrm{cc})$ and severe postpartum hemorrhage $(>1000 \mathrm{cc})$ were respectively $6.49 \%$ against $9.33 \%(p=0.358)$ and $1.29 \%$ against $2.66 \%(\mathrm{p}=0.114)$. A decrease in the average haemoglobin (Table 4) level was observed in both groups without much statistical difference: $0.38 \mathrm{~g} / \mathrm{dl}$ against 0.29 $\mathrm{g} / \mathrm{dl}(\mathrm{p}=0.99)$. The same trend was observed for the mean haematocrit value (Table 6): $0.99 \%$ in the misoprostol group against $0.59 \%$ in the oxytocin group (p $=0.796)$.

Table 2: Average systolic blood pressures and diastolic before and after childbirth.

\begin{tabular}{|c|c|c|c|c|}
\hline $\begin{array}{l}\text { Bood } \\
\text { pressure } \\
\text { (Average } \\
\text { /cm Hg) }\end{array}$ & $\begin{array}{l}\text { Misoprostol } \\
(\mathbf{N}=154)\end{array}$ & $\begin{array}{l}\text { Oxytocin } \\
(\mathrm{N}=150)\end{array}$ & $\begin{array}{l}\text { IC } \\
95 \%\end{array}$ & p \\
\hline SBP before & $12.15 \pm 1.4$ & $12.48 \pm 1.7$ & $\begin{array}{l}(-0.15 \\
0.71)\end{array}$ & $\begin{array}{l}0.06 \\
0\end{array}$ \\
\hline SBP after & $11.45 \pm 1.2$ & $11.89 \pm 1.4$ & $\begin{array}{l}(-0.16 ; \\
0.46)\end{array}$ & $\begin{array}{l}0.34 \\
8\end{array}$ \\
\hline $\begin{array}{l}\text { SBP } \\
\text { reduction }\end{array}$ & $0.7 \pm 1.6$ & $0.79 \pm 1.4$ & $\begin{array}{l}(-0.20 \\
0.50)\end{array}$ & $\begin{array}{l}0.41 \\
6\end{array}$ \\
\hline $\begin{array}{l}\text { DBP } \\
\text { before }\end{array}$ & $7.68 \pm 1.01$ & $7.79 \pm 1.2$ & $\begin{array}{l}(-0.14 ; \\
0.37)\end{array}$ & $\begin{array}{l}0.38 \\
0\end{array}$ \\
\hline DBP after & $7.14 \pm 1.07$ & $7.29 \pm 1$ & $\begin{array}{l}(-0.09 ; \\
0.40)\end{array}$ & $\begin{array}{l}0.22 \\
6\end{array}$ \\
\hline $\begin{array}{l}\text { DBP } \\
\text { reduction }\end{array}$ & $0.54 \pm 1.3$ & $0.5 \pm 1.2$ & $\begin{array}{l}(-0.38 ; \\
0.20)\end{array}$ & $\begin{array}{l}0.54 \\
8\end{array}$ \\
\hline
\end{tabular}

$\mathrm{SBP}=$ systolic blood pressure; $\mathrm{DBP}=$ diastolic blood pressure; $\mathrm{IC}=$ confidence interval; Student test

Table 3: Distribution of the patients according to the volume of the blood losses.

\begin{tabular}{|lllll|}
\hline Bood losses $(\mathrm{ml})$ & Misoprostol $(\mathbf{N}=154) \mathbf{N} \%$ & Oxytocin $(\mathbf{N}=150) \mathbf{N} \%$ & IC 95\% & P \\
\hline BL average * & $196.5 \pm 210$ & $208.4 \pm 324$ & $(-47.63 ; 75.49)$ & 0.656 \\
\hline $\mathrm{BL}<300 * *$ & 13487 & 13288 & $/$ & 0.795 \\
\hline $\mathrm{BL}<500 * *$ & 14493.5 & 13690.6 & $/$ & 0.359 \\
\hline $\mathrm{BL} \geq 500 * *$ & 106.5 & 149.3 & $/$ & 0.614 \\
\hline $\mathrm{BL} \geq 1000 * * *$ & 21.3 & 42.6 & $/$ & 0.443 \\
\hline
\end{tabular}

$\mathrm{BL}=$ blood losses $; \mathrm{ml}=$ milliliters $; \mathrm{IC}=$ confidence; interval $*$ Student test $; * *$ Khi 2 test; *** Fischer test 
The realization of medical treatment (additional administration of oxytocin and blood transfusion) or obstetrical (artificial issuance and/or uterine revision) was similar in both groups (Table 5).

Table 4: Rate of haemoglobin and haematocrit before and after the childbirth.

\begin{tabular}{|lllll|}
\hline Blood pressure (average / $\mathrm{cm} \mathrm{Hg}$ ) & Misoprostol $\mathbf{N}=154$ & Oxytocin $\mathbf{N}=150$ & IC 95\% & P value \\
\hline Hb before & $11.4 \pm 1.5$ & $11.3 \pm 1.6$ & $(-0.48 ; 0.29)$ & 0.629 \\
\hline Hb after & $11.08 \pm 1.9$ & $11.08 \pm 2$ & $(-0.47 ; 0.49)$ & 0.964 \\
\hline Hb reduction & $0.38 \pm 0.9$ & $0.29 \pm 1.3$ & $(-0.37 ; 0.18)$ & 0.489 \\
\hline Hc before & $35.6 \pm 3.8$ & $35.5 \pm 4.6$ & $(-1.17 ; 0.89)$ & 0.789 \\
\hline Hc after & $34.6 \pm 5$ & $34.9 \pm 6.1$ & $(-1.09 ; 1.63)$ & 0.701 \\
\hline Hc reduction & $0.9 \pm 2.8$ & $0.59 \pm 3.5$ & $(-0.94 ; 0.60)$ & 0.669 \\
\hline
\end{tabular}

$\mathrm{Hb}=$ haemoglobin $; \mathrm{Hc}=$ hematocrit $; \mathrm{cm}=$ centimeter; $\mathrm{IC}=$ confidence interval; Student test

The occurrence of side effects (Table 6) was mostly observed in the misoprostol group: $13.64 \%$ against $3.4 \%$ in the oxytocin group $(\mathrm{p}=0.004)$. Shivering occurred significantly more $(\mathrm{p}=0.001)$ in patients who received misoprostol compared to those who received oxytocin. $7.14 \%$ against $2 \%$ respectively. No significant difference was observed for other side effects: hyperthermia $(p=0.123)$. Nausea $(p=0.123)$. Vomiting $(p=0.498)$.

Table 5: Distribution of the patients according therapeutic aspects.

\begin{tabular}{|llll|} 
& $\begin{array}{l}\text { Misoprostol } \\
(\mathbf{N}=154)\end{array}$ & $\begin{array}{l}\text { Oxytocin } \\
(\mathbf{N}=150)\end{array}$ & p \\
& $\mathbf{N} \%$ & $\mathbf{N} \%$ & \\
\hline Uterotonics & 74.5 & 64 & 0.814 \\
\hline AR and/or UR & 53.2 & 32 & 0.723 \\
\hline Transfusions & 53.2 & 74 & 0.525 \\
\hline
\end{tabular}

$\mathrm{AR}=$ artificial removal of placenta; $\mathrm{RU}=$ uterine revision Fischer test

Table 6: Side effects.

\begin{tabular}{|llll|}
\hline & $\begin{array}{l}\text { Misoprostol } \\
(\mathbf{N}=154)\end{array}$ & $\begin{array}{l}\text { Oxytocin } \\
(\mathbf{N}=150)\end{array}$ & p \\
\hline Shivering* & 117.14 & 32 & 0.029 \\
\hline Hyperthermia & 42.59 & 10.6 & 0.371 \\
Vomiting & 21.29 & 10.8 & 1.000 \\
\hline Nausea & 42.59 & 10.6 & 0.371 \\
\hline Total* & 2113.64 & 63.8 & 0.004 \\
\hline
\end{tabular}

$*$ Odd Ratio $=3.7 ;$ IC $95 \%=(1,030 ; 13,792) ;$ Fischer test

\section{DISCUSSION}

In Senegal maternal mortality due to haemorrhage is a public health concern. Indeed with a 1 in 16 risk. PPH accounts for $25 \%$ of maternal deaths. ${ }^{2}$ However due to insufficient personnel (which is reflected in the fact that only $52 \%$ of births are attended by staff members). storage conditions for oxytocin that are not always met especially in healthcare facilities and climate conditions with temperatures varying between $40^{\circ} \mathrm{C}$ and $45^{\circ} \mathrm{C}$ over several months of the year (from June to October) the use of misoprostol for AMSTL is worth being assessed in the context of Senegal. ${ }^{2}$

Misoprostol is a drug of choice for the prevention of postpartum haemorrhage owing to its strong uterotonic properties which. when associated with pharmacodynamics. enable a swift onset of action within 2 minutes and a peak plasma concentration within 7 minutes. ${ }^{14}$ Unresolved issues relate to the route of administration and the ideal dosage for satisfactory effectiveness. with as few adverse effects as possible.

Our results will be mainly measured against those of authors who administered misoprostol and oxytocin doses comparable to ours. with emphasis on a clear indication that the AMTSL procedure of controlled cord traction was observed.

\section{Effectiveness}

The relevance of measuring blood pressure is to assess the impact haemorrhage has on the general condition which is one of the criteria proposed to define postpartum haemorrhage. ${ }^{15}$ This assessment is particularly useful in the context of anaemia where haemorrhagic shock can occur when less than $500 \mathrm{ml}$ of blood is lost. Cook and El Refaey observed similar results to ours when they respectively compared 500 and $400 \mathrm{mcg}$ of oral misoprostol to higher doses of oxytocin (10 IU IM) administered on its own or associated with methylergometrine. ${ }^{17.18}$

However these findings differ from those of Diab in Egypt who reported a higher drop in the blood pressure of the group receiving $400 \mathrm{mcg}$ of rectally administered misoprostol than the group receiving 5 IU oxytocin associated with $0.25 \mathrm{mg}$ of methylergometrine administered by intramuscular route. ${ }^{8}$ This could be due to the methylergometrine which has hypertensive properties. 
Measurement of blood loss during delivery is rarely practiced within our African work environment were collection bags are hardly affordable. Moreover visual estimates tend to miscalculate the amount of blood lost for it is partly absorbed by the patient's linen. There was no significant difference in the amount of blood loss between the two groups during our trial. The dose of 400 mcg of misoprostol administered per os per lingual. Or even rectally (10.22) was as effective as oxytocin $10 \mathrm{IU}$ IM. ${ }^{9,19-21}$ In these studies. The average volume of blood loss varied between $155 \mathrm{ml}$ and $193.5 \mathrm{ml}$ in patients who received misoprostol; close to the average volume of $196.5 \mathrm{ml}$ observed in our study.

However, Villar in a systematic review that focused on the use of misoprostol in preventing early postpartum haemorrhage indicated the greater effectiveness of other conventional uterotonics (oxytocin, methylergometrine) for the reduction of blood loss during delivery compared to misoprostol. ${ }^{23}$

In our study. A comparison of the occurrence of PPH (> $500 \mathrm{ml}$ ) in the two groups did not reveal any significant difference. As was also observed by Walley. Afolabi. And Kundodyiwa with $400 \mathrm{mcg}$ of oral misoprostol for use with AMTSL. ${ }^{9.19 .24}$ The frequency of PPH was $6.49 \%$ in our study. But zero for Walley and Afolabi. ${ }^{9.19}$ It was $2.6 \%$ for Zacharia and $\mathbf{1 5 . 2 \%}$ for Kundodyiwa using 400 mcg per os (the delivery technique was not specified). ${ }^{19.24}$ Bellad. Without specifying the delivery technique either. Observed a greater effectiveness of $400 \mathrm{mcg}$ of perlingual misoprostol over $10 \mathrm{IU}$ of oxytocin for the prevention of PPH. $^{21}$

As noted by Walley. Zachariah. Afolabi. Bellad and Kundodyiwa. a dose of $400 \mathrm{mcg}$ of misoprostol seemed as effective as $10 \mathrm{IU}$ of oxytocin for the prevention of severe PPH. ${ }^{9.19-21.24}$

In Turkey, Caliskan observed a slightly higher number of severe PPH cases but without much substantial difference between the group being rectally administered $400 \mathrm{mcg}$ of misoprostol under AMTSL and the control group receiving oxytocin (10 IU drips); however this population comprised high-risk patients for postpartum haemorrhage (anaemia, hydramnios, pre-eclampsia). ${ }^{22}$ The same trend was observed by Villar who indicated that after the integration of 3 randomized clinical trials. Severe PPH was more frequent in the misoprostol group than for patients who received conventional injectable uterotonics. $^{23}$

With a dose of $400 \mathrm{mcg}$ (per os or perlingual). the incidence of severe PPH observed in our work $(1.29 \%)$ was higher than that reported by Walley $(0 \%)$ and Zacharia $(0.1 \%)$. but lower than that of Kundodyiwa $(3.7 \%) .^{9,19,24}$ It shall be noted that Bamigboye and Caliskan with $400 \mathrm{mcg}$ administered rectally and El Refaey with 500 mcg per os. reported comparable effectiveness to oxytocin 10 IU IM for the prevention of severe PPH. ${ }^{7,18,21}$

We noted no statistically significant difference between the two groups based on the average hemoglobin and haematocrit levels before and after delivery. Cook who noted a higher reduction in hemoglobin levels in the misoprostol group (400 mcg per os) compared to the control group (oxytocin or syntometrine) suggested a greater effectiveness of this combination therapy. ${ }^{17}$ However. Our results are consistent with those of Bulgaho, Walley, Zachariah, Afolabi and Caliskan who orally or rectally administered doses of 400 to $500 \mathrm{mcg}$ of misoprostol comparing it to oxytocin or

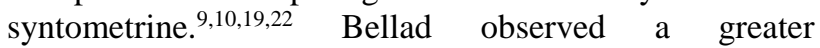
effectiveness of $400 \mathrm{mcg}$ of misoprostol via the perlingual route over $10 \mathrm{IU}$ IM oxytocin. ${ }^{21}$

The need for additional oxytocics to limit blood loss is another criterion for measuring the therapeutic effectiveness of uterotonics used as first-line treatment. In our trial, the proportion of patients who were administered additional doses of oxytocics was comparable in both groups. Oxytocic requirements we observed in the misoprostol group were lower than those reported by Hofmeyr with $8.4 \%$ for $400 \mathrm{mcg}$ via the oral route. El Refeay with $14 \%$ for 500 mcg per os. And Cook with $22 \%$ for $400 \mathrm{mcg}$ per os. ${ }^{17,18,25}$ No superiority of one treatment over the other was noted in the various studies where 400/500 mcg of misoprostol per os/perlingual was compared to oxytocin and/or Syntometrine ${ }^{9} .^{9,10,19,21,23}$ It shall be noted that Cook. Comparing $400 \mathrm{mcg}$ of orally administered misoprostol to oxytocin and/or Syntometrine ${ }^{\circledR}$. Observed a higher relative risk $(\mathrm{RR}=$ 2.89 ) in the group receiving misoprostol. ${ }^{17}$ The difference observed in this study could be attributed to an interventionist treatment protocol where an additional dose was administered when blood loss reached a threshold of $300 \mathrm{cc}$.

Indications for blood transfusion vary widely from one team to another and depend mainly on the clinical condition of the patient, hematological parameters, protocols and the availability of blood products. We recorded a transfusion rate of $3.2 \%$ in the misoprostol group and hence no statistical difference with the $4.6 \%$ rate in the oxytocin group. Transfusion requirements reported in AMTSL with misoprostol are variable: $0 \%$ for Walley (400 mcg per os), $0.1 \%$ for Zachariah (400 mcg perlingual), $0.6 \%$ for Bulgaho (400 mcg rectally), $2 \%$ for El Refeay (500 mcg per os) and 3\% for Caliskan in Turkey who reported an identical value to ours., , $^{9,18,19,22}$ In these studies. There was no statistically significant difference with the control group that received 10 IU IM oxytocin. Only the oxytocin-methylergometrine combination seems to reduce in a statistically significant manner. The need for blood products with a rate of $3 \%$ in the misoprostol group against $1 \%$ in the group that received this combination $(\mathrm{p}<0.05) .^{22}$ 
The therapeutic effectiveness of uterotonics can be assessed on the basis of the manual removal of the placenta and/or uterine examination required. No significant difference was observed between misoprostol groups administered doses of $400 / 500 \mathrm{mcg}$ via oral route (El-Refaey, Walley, Zachariah) or rectally and the control groups that received oxytocin or syntometrine. ${ }^{9,18,19,22}$ Rates reported with $400 \mathrm{mcg}$ oral/perlingual misoprostol doses are often low: $0 \%$ for Diab. $0.4 \%$ for Zachariah. $0.5 \%$ for Walley. Our rate $(3.2 \%)$ was quite close to that of Gulmezoglu $(2 \%) .{ }^{8,9,19,26}$

\section{Tolerance}

There were more side effects noted in the misoprostol group than in the oxytocin group. The difference between the groups lies in the occurrence of shivering, which was more frequent in the misoprostol group.

In our study, the relative risk of shivering in the misoprostol group was 3.8. Our observations were identical to those of most authors who had administered a $400 \mathrm{mcg}$ dose of misoprostol via the oral route rectally. ${ }^{9} 10,19,22,24,27$ However, it should be noted that the observed frequency in the misoprostol group in our study is close to the $9.3 \%$ reported by Zacharia and much lower than the $43.6 \%$ observed by Kundodyiwa. ${ }^{19,24}$ Higher levels are reported with an oral dose of $500 \mathrm{mcg}$ by $\mathrm{El}$ Refaey (72\%). For rectally administered doses (400 mcg), Bulgaho observed a frequency of $38.1 \%$ and $11.8 \%$ for Caliskan. ${ }^{10,18,22}$ El Refaey who administered an oral dose of $500 \mathrm{mcg}$ reported a record level of $72 \% .^{18}$ This is due to the fact that this side effect depends on the dosage and route of administration and appears to be more frequent when administered via the oral rather than the rectal route. The RR for a 400/500 mcg dose per os is 1.54 and 1.95 and rises to 3 and 4 for a $600 \mathrm{mcg}$ dose per os. ${ }^{12,18,27,28}$

The occurrence of fever in the event of misoprostol intake is due to its action on thermoregulatory centres. The incidence of fever observed in the 2 groups was not significant. Walley and Gupta are among the few authors to reach the same conclusion as we did. ${ }^{9.29}$ For our trial this could be due to the fact that side effects were monitored for only 6 hours. Whereas the peak incidence seemingly occurs between 6 and 12 hours after administration. ${ }^{26}$

The occurrence of nausea in our study was comparable in both groups. as is the case for Kundodyiwa. ${ }^{24}$ This occurrence rate of $2.59 \%$ that we observed is close to those reported for higher doses of misoprostol administered orally by Walley with $3.3 \%$ or rectally by Gutpa with $2.3 \%$. A very high occurrence rate of $31 \%$ was reported by El Refaey with $500 \mathrm{mcg}$ per os. While Lumbiganon observed no cases of nausea with $400 \mathrm{mcg}$ per os. ${ }^{9,18,27,29}$ Vomiting is one of the most frequent side effects of misoprostol especially when an oral dose is administered and its peak incidence apparently occurs quite early (1-2 hours after oral intake) and may be dosedependent. $^{27}$ in our trial however we observed no significant difference between the misoprostol group $(1.29 \%)$ and the oxytocin group $(0.6 \%)$. For a dose of $400 \mathrm{mcg}$, Lumbiganon did not report cases of vomiting and Zachariah and Kundodyiwa also reported low rates of $0.7 \%$ and $0.8 \%$ respectively. ${ }^{19,24,27}$

No cases of diarrhea were noted in our study although it is a common side effect. El-Refaey noted an $18 \%$ frequency rate with an oral dose of $500 \mathrm{mcg} .{ }^{18}$ According to Lumbiganon, this side effect occurs following an oral intake especially between the 6th and 12th hour, which could explain why it was not observed in our study. Nonetheless. Occurrence rates reported for $400 \mathrm{mcg}$ oral doses are usually low: $0.7 \%$ for Zachariah and $0.8 \%$ for Kundodyiwa. ${ }^{18,23}$ It is also not very common among patients receiving oxytocin even with higher doses and different routes of administration. ${ }^{21,23,27}$

\section{CONCLUSION}

These results indicate that in the context of a tropical country like Senegal. Misoprostol (400 mcg per os) has comparable effectiveness to oxytocin (5 IU IV) for use with AMTSL in the prevention of early postpartum haemorrhage with the most frequent side effect being shivering with a view to achieving the Millennium Development Goals. Misoprostol is indeed a valid alternative to oxytocin for use with AMTSL within a hospital setting in order to reduce the risks of maternal death through postpartum haemorrhage in low-income Sub-Saharan African countries. It should be included as an alternative in delivery protocols and also added to the list of essential drugs for affordable access.

Funding: No funding sources

Conflict of interest: None declared

Ethical approval: The study was approved by the Institutional Ethics Committee

\section{REFERENCES}

1. WHO. Global estimates of maternal mortality for 1995: results of an in-depth review. analysis and estimation strategy. Geneva: WHO. 2001.

2. Direction de la statistique. Ministère de l'économie et des finances. Enquête démographique et de santé. Dakar. Sénégal. 2005.

3. Prendiville WJ. Harding JE. Elbourne DR. Stirrat GM. The Bristol third stage trial: active versus physiological management of the third stage of labour. BMJ. 1988;297(6659):1295-300.

4. Begley CA. Comparison of 'active' and 'physiological' management of the third stage of labour. Midwifery. 1990;6.1:3-17.

5. Khan GQ. John IS. Wani S. Teressa Doherti T. Sibai BM. Controlled cord traction versus minimal intervention techniques in delivery of the placenta: a 
randomized controlled trial. Am J Obstet Gynecol. 1997;177(4):770-4.

6. Prendiville WJ. Elbourne McDonald S. Active versus expectant management in the third stage of labour (Cochrane Review. March 9. 2000). In: The Cochrane Library. Issue 4. Oxford: Update Software. Ltd. 2001.

7. Bamigboye AA. Merrell DA. Hofmeyr GJ. Ronald Mitchell R. Randomized comparison of rectal misoprostol with syntometrine for management of third stage of labor. Acta Obstet Gynecol Scand. 1998;77(2):178-81.

8. Cook CM. Spurret B. Murray H. A randomized clinical trial comparing oral misoprostol with synthetic oxytocin or syntometrine in the third stage of labour. Aust NZ J Obstet Gynaecol. 1999;39(4):414-9.

9. Diab KM. Ramy AR. Yehia MA. The use of rectal misoprostol as active pharmacological management of the third stage of labor. J Obstet Gynaecol Res. 1999;25:327-32.

10. Walley RL. Wilson JB. Crane JM. Matthews K. Sawyer E. Hutchens D. A double-blind placebo controlled randomized trial of misoprostol and oxytocin in the management of the third stage of labour. BJOG. 2000;107:1111-5.

11. Bulgaho A. Daniel A. Faundes A. Cunha M. Misoprostol for prevention of postpartum hemorrhage. Int J Gynec Obstet. 2001;73:1-6.

12. Ng PS. Chan ASM. Sin WK. Tang LCH. Cheung KB. Yuen PM. A multicentre randomized controlled trial of oral misoprostol and i.m. syntometrine in the management of the third stage of labour. Hum. Reprod. 2001;16:31-5.

13. Gülmezoglu AM. Forn F. Villar J. Hofmeyr GJ. Prostaglandins in prevention of postpartum hemorrhage. Cochrane Data base Syst Rev. 2007;(3):CD 000494.

14. Darney PD. Misoprostol: a boon to safe motherhood or not? Lancet. 2001;358(9283):682-3.

15. Tang OS. Schweer H. Seyberth HW. Lee SW. Ho PC. Pharmacokinetics of different routes of administration of misoprostol. Hum Reprod. 2002;17(2):332-6.

16. Bose P. Regan F. Paterson-Brown S. Improving the accuracy of estimated blood loss at obstetric haemorrhage using clinical reconstructions. BJOG. 2006;113(8):919-24.

17. El-Refaey H. Randa N. O’Brien P. Mona A. Geary M. Jane W. Choulnard CR. The misoprostol third stage of labour study: a randomised controlled comparison between orally administered misoprostol and standard management. BJOG. 2000;107(9):1104-10.

18. Afolabi EO. Kuti O. Orji O. Ogunniyi SO. Oral misoprostol versus intramuscular oxytocine in the active management of the third stage of the labour. Singapore Med J. 2010;51(3):207-11.

19. Zachariah ES. Naidu M. Seshadri L.nOral misoprostol in the third stage of labor. Int J Gynecol Obstet. 2006;92:23-6.

20. Chaudhuri P. Biswas J. Mandal A. Sublingual misoprostol versus intramuscular oxytocin for prevention of postpartum hemorrhage in low-risk women. Int J Gynecol Obstet. 2012;112(2):148-2.

21. Caliskan E. Meydanli MM. Dilbaz B. Aykan B.. Sonmezer M. Haberal A. Is rectal misoprostol really effective in the treatment of third stage of labor? A randomized controlled trial. Am J Obstet Gynecol. 2002;187(4):1038-45.

22. Singh G. Radhakrishnan G. Guleria K. Comparaison of misoprostol sublingual. intravenous oxytocin and intravenous methylergometrine in active management of third stage of labour. Int J Gynecol Obstet. 2009;107:130-4.

23. Villar J. Gulmezoglu AM. Hofmeyr GJ. Forna F. Systematic review of randomized controlled trials of misoprostol to prevent postpartum hemorrhage. Obstet Gynecol. 2002;100:1301-12.

24. Kundodyiwa TW. Myor F. Rusakanik S. Misoprostol versus oxytocin in the third stage of labour. Int $\mathbf{J}$ Gynaecol Obstet. 2001;75:235-41.

25. Vimala N. Mittal S. Kumar S. Dadhwal S. Mehta S. Sublingual misoprostol versus methylergometrine for active management of third stage of labour. Int $\mathrm{J}$ Gynecol Obstet. 2004;87:1-5.

26. Hofmeyr GJ. Nikodem VC. De Jager M. Gelbart BR. A randomized placebo controlled trial of oral misoprostol in the third stage of labour. Br J Obstet Gynaecol. 1998;105:971-5.

27. Gülmezoglu AM. Villar J. Thi Nhu Ngoc N. Piaggio G. Carroli G. Adetoro L. et al. WHO multicentre randomised trial of misoprostol in the management of the third stage of labour. Lancet. 2001;358:68995.

28. Lumbiganon P. Villar J. Piaggio G. Gulmezoglu M. Side effects of oral misoprostol during the first 24 hours after administration in the third stage of labour. BJOG. 2002;109:1222-6.

29. Oboro VO. Tabowei TO. J Obstet Gynaecol. 2003;23:13-6.

30. Gupta B. Jain V. Aggarwal N. Rectal misoprostol versus oxytocin in the prevention of postpartum hemorrhage- a pilot study. Int J Obstet Gynecol. 2006;94 suppl 2:s139-40.

Cite this article as: Diallo M, Sylla T, Diouf AA, Moreira PM, Gassama O, Gueye MDN, et al. Active management of third stage of labour with low doses of oral misoprostol and oxytocin on low: risk parturient in a Sub-Saharan hospital, Dakar, Sénégal. Int J Reprod Contracept Obstet Gynecol 2017;6:51622. 